\title{
Robust Wind Turbine System against Voltage Sag with Induction Generators Interfaced to the Grid by Power Electronics Converters
}

\author{
Marta Molinas Member (Norwegian University of Science and Technology) \\ Bjarne Naess Non-member (Norwegian University of Science and Technology) \\ William Gullvik Non-member (Norwegian University of Science and Technology) \\ Tore Undeland Non-member (Norwegian University of Science and Technology)
}

Keywords: grid code, voltage sag, cage induction generator, back to back converters, DC link control, vector control

The emergence of new grid codes will pose wind turbine developers a new challenge: the ride through capability during voltage sags. This means that with a high penetration of wind power in the network, the wind turbines/wind farms should be able to continuously supply the network during voltage sags. One of such grid code voltage sag profile for ride through is shown in Fig. 1 for illustration. These new grid codes which are in progress both in Norway and several other countries will most likely influence the type of electrical system (generator and network interface) of future wind turbines. To cope with this new challenge several industries have already initiated research efforts oriented at developing ride through capability technology.

Among the technology choices, squirrel cage induction machines are a very attractive choice for wind power generation because they are robust, inexpensive and have low maintenance requirement and cost. As network interface, the use of back-to-back converters for variable speed operation is extensively reported in the literature showing their capability to achieve maximum energy capture in a wide range of wind conditions. There is however little reference to the control of back to back converters for low voltage ride-through capability of wind farms connected to the network.

In this paper we analyze an electrical system for wind turbines with cage induction generators interfaced to the grid with back to back converters, and experimentally evaluate the ride through capability under a symmetrical short circuit in the power system.

A $55 \mathrm{~kW}$ motor-generator set of squirrel cage induction machines with a wind emulator to control the torque is used as model for the wind farm. This set-up is connected to the grid through back to back converters, as schematically shown in Fig. 2. The rating of the machines used in this experiment is of relevance in this paper because at this rating the p.u. values are close to those of real wind turbines and thus the performance is representative of real cases.

The purpose of this experiment is to evaluate the role of the power electronics converter as a grid interface under short circuit conditions for the most common and inexpensive type of generator: the squirrel cage induction generator. Standard vector control techniques are implemented, aimed at keeping the DC link voltage constant to ensure power balance during the short circuit. Experimental results show a very stiff DC link control which proves the robustness of the back to back converters against voltage sags.

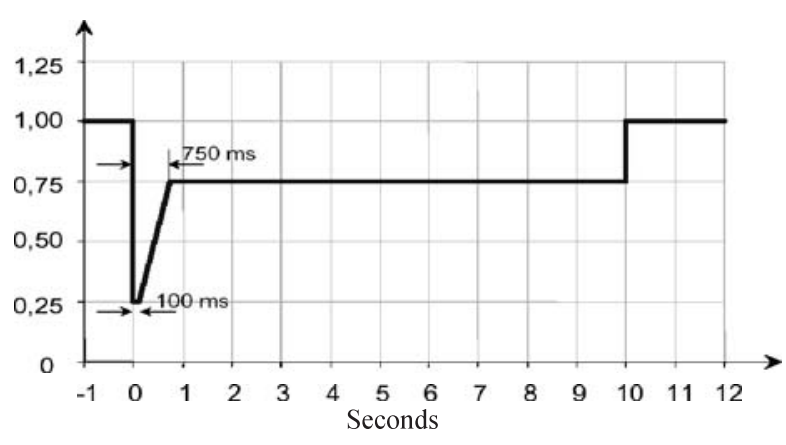

Fig. 1. Eltra grid code voltage profile

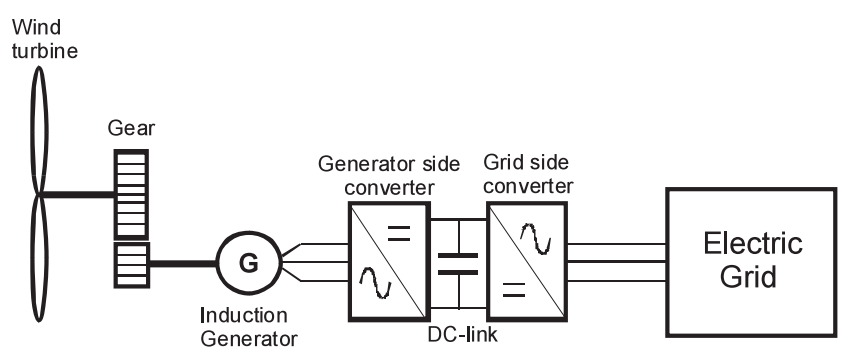

Fig. 2. Schematic representation of the system 


\title{
Robust Wind Turbine System Against Voltage Sag with Induction Generators Interfaced to the Grid by Power Electronic Converters
}

\author{
Marta Molinas* Member \\ Bjarne Naess* Non-member \\ William Gullvik* Non-member \\ Tore Undeland* Non-member
}

\begin{abstract}
An electrical system for wind turbines using cage induction generator with back to back converters for connection to the network is experimentally tested under short circuit conditions in a $55 \mathrm{~kW}$ generator set-up. $50 \%$ voltage sag is realized in the laboratory set-up to investigate the performance of the power electronic converters control under the newly introduced grid codes. Standard vector control techniques are implemented with the aim to maintain balance between generated power and power supplied to the grid. The robustness of the power electronics converter is experimentally analyzed under the short circuit for different settings of the converter nominal current and the converters are found to be robust against voltage sags.
\end{abstract}

Keywords: grid code, voltage sag, cage induction generator, back to back converters, DC link control, vector control

\section{Introduction}

The emergence of new grid codes will pose wind turbine developers a new challenge: the ride through capability during voltage sags. This means that with a high penetration of wind power in the network, the wind turbines/wind farms should be able to continuously supply the network during voltage sags. One of such grid code voltage sag profile for ride through is shown in Fig. 1 for illustration ${ }^{(1)}$. These new grid codes which are being proposed in Norway ${ }^{(2)}$ and several other countries ${ }^{(3)}$ will most likely influence the topology of the electrical system (generator and network interface) of future wind turbines. To cope with this new challenge several industries have already directed research efforts to the development of ride through capability ${ }^{(4)(5)}$.

Among the technology choices, squirrel cage induction machines are a very attractive choice for wind power generation because they are robust, inexpensive and have low maintenance requirement and cost. As network interface, the use of back-to-back converters for variable speed operation is extensively reported in the literature ${ }^{(6)-(8)}$ showing their capability to achieve maximum energy capture in a wide range of wind conditions. There is however little reference to the control of back to back converters for low voltage ride-through capability of wind farms connected to the network ${ }^{(9)(10)}$.

In this paper we analyze an electrical system for wind turbines with cage induction generators interfaced to the grid with back to back converters, and experimentally evaluate the ride through capability under short circuit in the power system for different setting conditions of the converters. A $55 \mathrm{~kW}$ motor-generator set of squirrel cage induction machines with a wind emulator to control the torque is used as

\footnotetext{
* Norwegian University of Science and Technology

O.S. Bragstad plass 2E, 7491 Trondheim, Norway
}

model for the wind farm. This set-up is connected to the grid through back to back converters, as schematically shown in Fig. 2. The purpose of the experiment in this paper is to evaluate the role of the power electronics converter as a grid interface under short circuit conditions for the most common and inexpensive type of generator: the squirrel cage induction generator. Standard vector control techniques are implemented, aimed at keeping the DC link voltage constant or rising to a safe value to ensure power balance during the short circuit. Experimental results show a very stiff DC link control which proves the robustness of the back to back converters

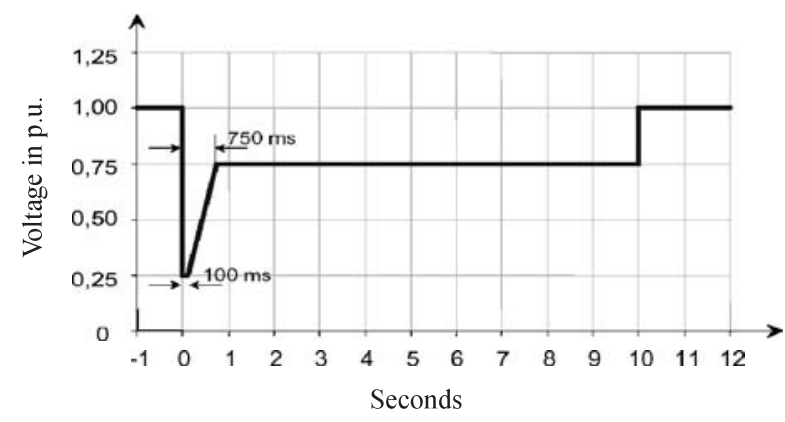

Fig. 1. Eltra grid code: voltage profile

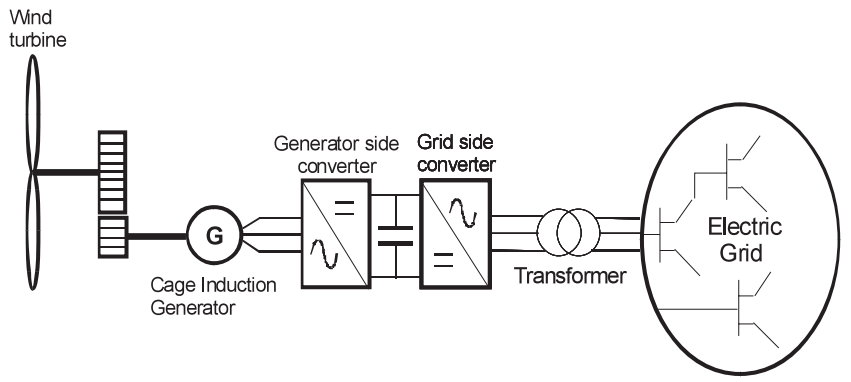

Fig. 2. Schematic representation of the system 
against voltage sags.

\section{Control Strategy}

Wind turbines are normally programmed to drop out when there is a $30 \%$ voltage drop. Local and remote faults on the grid produce voltage dips that cause wind turbines to trip. With the growing generating capacity of wind farms, utilities are concerned about the stability of the whole system and are proposing grid codes for wind that will request wind farms to ride-through grid disturbances, remaining on-line and supplying the system. Without power electronics solution as interface between wind generation and grid, compliance with low voltage ride-through will be a hard to accomplish goal. Given the choice of the power electronics solution, the control algorithm of the power electronics converters almost entirely determines the performance and is therefore critical to ensure ride-through. Looking upon this problem, we propose a control strategy for the power converters in the event of a voltage sag in the grid side. Standard vector control techniques are implemented and tested on both, generator and grid side converters. By doing so, on the generator side converter we get decoupled control of electromagnetic torque and flux and on the grid side converter we get decoupled control of active and reactive power. The control of the DC link voltage is made in a coordinated fashion between generator and grid side converters in a way that is explained in detail in the following subsections.

2.1 Control of the Grid Side Converter The aim of the grid side converter is to regulate the DC link voltage $V_{d c}$ and maintain the balance between the DC link power and power supplied to the grid. This is done by actively controlling the direct axis current component of the converter. To do that, the converter 3 phase currents and voltages are expressed in a two axis reference frame synchronously rotating at the grid frequency. The voltage at the grid side is expressed as

$$
V_{a b c}=R i_{a b c}+L \frac{d i_{a b c}}{d t}+V_{a b c, c o n v}
$$

where $V_{a b c}, i_{a b c}, V_{a b c, c o n v}$ are grid voltages, grid currents, and voltage of the front end converter, $R$ and $L$ are the resistance and inductance between the converter and the grid. Equation (1) is then transformed into a dq reference frame rotating at the grid frequency $\omega$.

$$
V_{d q}=R i_{d q}+L \frac{d i_{d q}}{d t}+L\left[\begin{array}{cc}
0 & -\omega \\
\omega & 0
\end{array}\right] i_{d q}+V_{d q_{c o n v}} \cdots \cdots
$$

Aligning the $d$ axis of the Park reference frame with the grid voltage vector we have that $v_{q}=0$. The angular position of the supply voltage vector is computed as

$$
\theta_{v}=\tan ^{-1}\left(\frac{v_{\beta}}{v_{\alpha}}\right)
$$

where $v_{\alpha}$ and $v_{\beta}$ are the components of the stator voltage in a stationary two axis reference frame (Clark transformation). In order to mitigate the effect of measurement errors, the angle computed in (3) is then filtered by a PLL whose transfer function can be expressed as

$$
\hat{\theta}_{v}=\frac{1}{1+2 \frac{\zeta}{\omega_{0}} s+\frac{s^{2}}{\omega_{0}^{2}}} \cdot \theta_{v}
$$

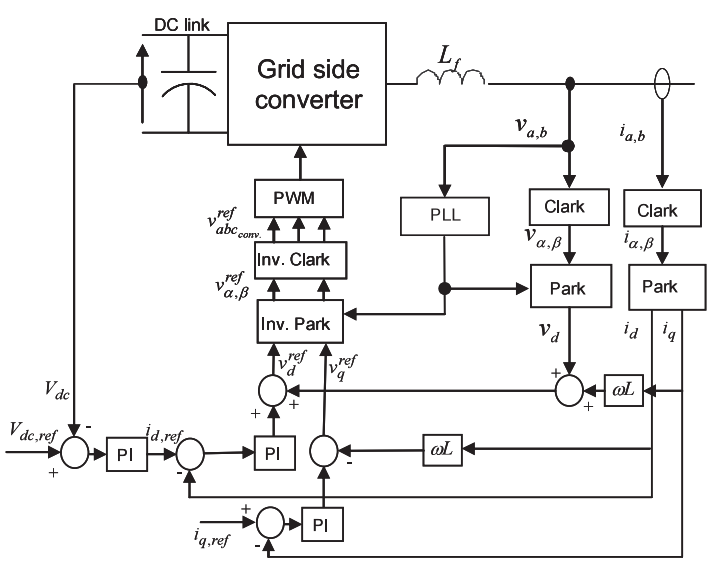

Fig. 3. Control of the grid side converter

Damping factor $\zeta$ and natural frequency $\omega_{0}$ of the PLL are chosen so to achieve a fast transient response while keeping a reasonable filtering action. The better the quality of the voltage measurements, the quickest the PLL response can be.

The power balance between the DC link and the grid side converter output gives

$$
V_{d c} i_{d c}=\frac{3}{2} v_{d} i_{d}
$$

where $V_{d c}$ is the DC link voltage and $i_{d c}$ is the DC link current. In equation (5) $v_{d}$ is determined by the depth of the voltage sag, and the DC link voltage can be controlled by modulating the converter direct axis current component $i_{d}$.

The converter quadrature current component $i_{q}$ is used to modulate the flow of reactive power. In our case, the reactive power reference is set to zero, to obtain unity power factor and at the same time to have the full range of the IGBT available to boost the direct current component $i_{d}$ during the fault. The DC link voltage is regulated at $650 \mathrm{~V}$ and the threshold value for which the protection is triggered is fixed to $740 \mathrm{~V}$. Fig. 3 shows the block diagram of the control of the grid side converter. In the grid side converter, the inner control loop has been tuned according to the same modulusoptimum technique, starting from the value of the filter inductance at the converter output. Also the DC link controller has been calculated in the same way, taking into consideration the amount of capacitance used.

2.2 Control of the Generator Side Converter The cage induction generator is controlled using sensorless vector control, with currents and voltages referred to a dq synchronous frame with the $\mathrm{d}$ axis aligned along the rotor flux vector position. This allows decoupled control of electromagnetic torque and reactive power. To calculate the rotor flux vector, first the stator flux is evaluated by integrating the stator voltage:

$$
\psi_{s}=\int\left(v_{s}-R_{s} \cdot i_{s}\right) d t
$$

Drift of the open loop integration is avoided by forcing the stator flux vector to follow a circular trajectory on the $\alpha-\beta$ plane, as proposed in (11). Rotor flux is then evaluated as

$$
\psi_{r}=\psi_{s}-L_{\sigma} i_{s}
$$

Above, $\psi_{s}, \psi_{r}$ are stator and rotor fluxes, $L_{\sigma}$ is the leakage inductance, and $i_{s}$ is the stator current. The $\alpha-\beta$ components 


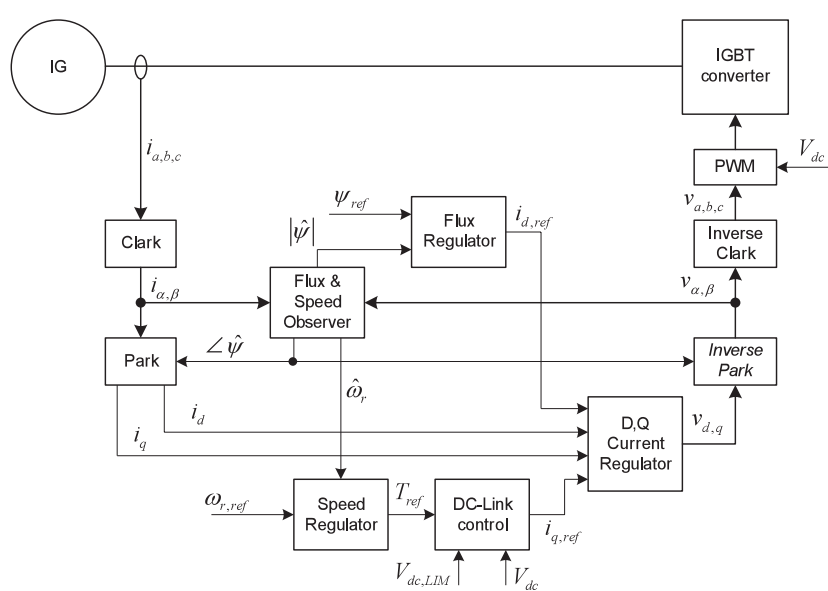

Fig. 4. Control of the generator side converter

of the flux are used to calculate the electrical angle $\theta_{\psi}$ of the rotor flux position used in the Park transformations in order to achieve field orientation.

The electromagnetic torque of the induction machine is calculated as

$$
T_{e}=\frac{2}{3} P \frac{L_{m}}{L_{r}} \psi_{d} i_{q} \ldots \ldots \ldots \ldots \ldots \ldots \ldots \ldots \ldots
$$

where $\mathrm{P}$ is the number of pole pairs, $\psi_{d}$ is the $\mathrm{d}$ component of the rotor flux, $L_{m}, L_{r}$ are the magnetizing and rotor inductances respectively, $i_{q}$ is the torque producing current and used to control the electromagnetic torque. This will in turn control the active power flow and thus the voltage level of the DC link. Fig. 4 shows the block diagram of the control of the generator side converter. Control parameters of the generator side converter were calculated by using standard modulus-optimum pole placements, starting from generator parameters.

During normal operation, the generator is speed controlled to a set point that can be calculated so to maximize the power that can be transferred from the turbine. When severe voltage sag occurs on the grid side, the front-end converter may reach its current limits and will not be able to transfer the whole amount of power coming from the turbine to the faulty line. As a result of the power imbalance, the DC link voltage will increase from the normal operation set-point. The generator-end converter will sense this increase and will automatically regulate the torque so that the DC link does not increase above a safety value, allowing the system to ride through a short fault.

\section{Experimental Set-up}

Fig. 5 shows the experimental configuration and data acquisition system. Ratings of experimental devices and components are shown in Table 1 . A $55 \mathrm{~kW}, 380 \mathrm{~V}, 110 \mathrm{~A}, 50 \mathrm{~Hz}$, 6 poles cage induction machine is utilized as generator in the experimental set-up. Two non commercial converters prototypes with $5 \mathrm{kHz}$ switching frequencies are used. An inductor of $1 \mathrm{mH}$ is connected after the grid side converter as filter. The three phase short circuit is emulated using a short circuit device composed of three anti parallel thyristor stack connected in shunt to the line via a short circuit inductor of $0.5 \mathrm{mH}$. The whole set-up is then connected to the utility bus

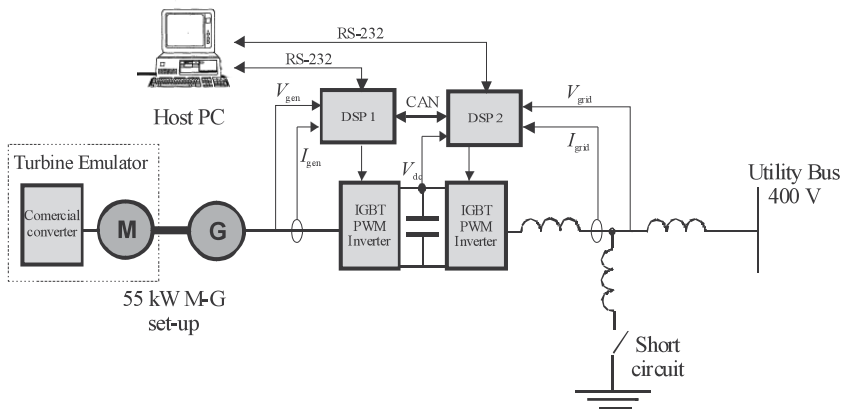

Fig. 5. Experimental configuration and data acquisition system

Table 1. Ratings of experimental devices

\begin{tabular}{|l|l|}
\hline Cage induction machines (M-G set) & $\begin{array}{l}\text { Power rating: } 55 \mathrm{~kW} \\
\text { Rated speed: } 990 \mathrm{rpm} \\
\text { AC voltage: } 380 \mathrm{~V} \\
\text { Current: } 110 \mathrm{~A} \\
\text { Drive: commercial ABB inverter }\end{array}$ \\
\hline Line inductance & $\begin{array}{l}\text { Utility side: } 0.2 \mathrm{mH} \\
\text { Generation side: } 1 \mathrm{mH}\end{array}$ \\
\hline Power converters (IGBT) & $\begin{array}{l}\text { Switching frequency: } 5 \mathrm{kHz} \\
\text { DC link voltage: } 647 \mathrm{~V} \\
\text { DC link capacitance: } \\
\text { Current: } 110 \mathrm{~A}\end{array}$ \\
DSP: TMS320F2812 & $\begin{array}{l}\text { AC Voltage: } 400 \mathrm{~V} \\
\text { Current: } 2000 \mathrm{~A}(\mathrm{short} \text { circuit) }\end{array}$ \\
\hline Utility line & $\begin{array}{l}\text { Inductance: } 0.5 \mathrm{mH} \\
\text { Snubbers: C: } 220 \mathrm{nF} ; \mathrm{R}: 68 \mathrm{Ohm} \\
\text { Max. Current: } 2200 \mathrm{~A}\end{array}$ \\
\hline $\begin{array}{l}\text { Short circuit device } \\
\text { (Thyristor controlled) }\end{array}$ &
\end{tabular}

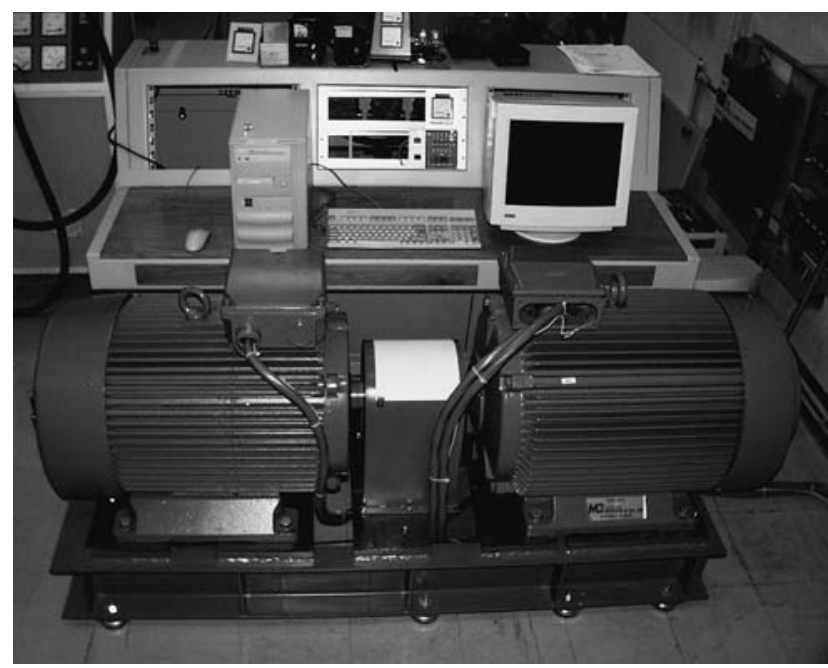

Fig. 6. The $55 \mathrm{~kW}$ motor-generator set used in the experiment

via three $0.2 \mathrm{mH}$ inductors that act as line impedance. The inductors were selected so as to produce the desired voltage sag and also to limit the short circuit current from the mains. One DSP is used for signal processing and control of each converter and communication between is achieved by means of a CAN bus. The DC link voltage is regulated to $650 \mathrm{~V}$. In the generator side, only two phase currents are measured, while the value of the DC link voltage is received from the line front-end system through the high speed CAN bus. At the grid side converter two line currents, two line voltages together with the DC link voltage are measured. The induction generator is driven by a second induction machine of 
$55 \mathrm{~kW}$ whose torque is controlled using a commercial frequency converter to have constant nominal torque. Fig. 6 shows the $55 \mathrm{~kW}$ motor-generator set-up used in experiments to emulate the wind turbine and wind generator. Fig. 7 shows the two back to back converters connected to the generator of

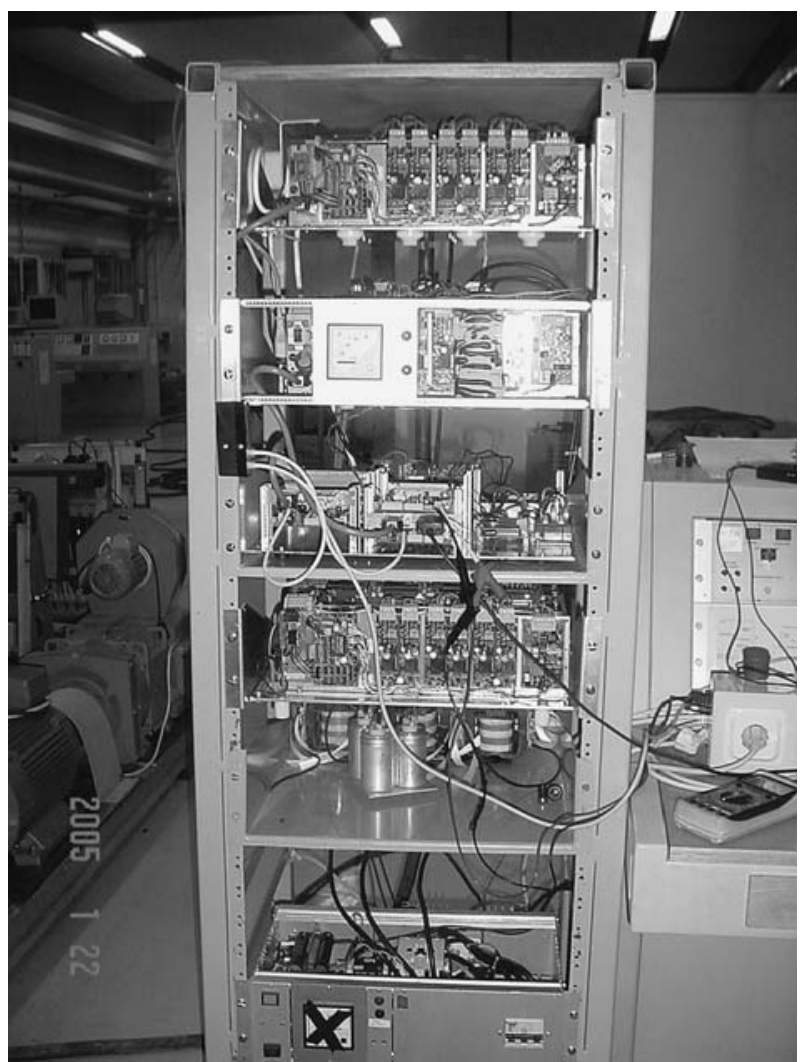

Fig. 7. Back to back converters of the experimental set-up
Fig. 6. The IGBTs of the converters used in the experiment were rated for $110 \mathrm{~A}(\mathrm{rms})$ with no short time overload. In the second test the current limit of the IGBTs was set to 0.8 p.u. to test the performance of the generator side converter controller. The short circuit was emulated by sending triggering signals to the thyristors so as to produce a short circuit for $100 \mathrm{~ms}$.

\section{Experimental Results}

Several short circuit trials have been made to achieve a voltage sag of $50 \%$. We operated the short circuit device previously described by giving a triggering signal to the thyristors for a short circuit duration of $100 \mathrm{~ms}$. The torque of the induction motor that drives the induction generator was set to give constant nominal the torque for all the tests. For the first experiment, the rating of the IGBTs was set to $110 \mathrm{~A}$ (1 p.u.). With the parameters of the experimental system shown in Table 1 we measured the voltages and currents shown in Fig. 8. In the first graph of Fig. 8, the line voltages $V_{a b}, V_{b c}$ are shown. At the instant the short circuit is activated we can observe a voltage reduction down to $0.5 \mathrm{p}$.u. In the second graph of Fig. 8, we have the DC link voltage $V_{d c}$ and the direct component $V_{d}$ of the line voltage. We can see that during the $100 \mathrm{~ms}$ of the short circuit the DC link voltage is very stiffly controlled to the preset value in the grid side converter controller. Imperceptible variations are observed during the short circuit, which means that a perfect decoupling of the generator from the grid was achieved; the generator did not sense there was a short circuit. This is the result of the balance between generated power and power supplied to the grid.

Active and reactive powers $P, Q$ are shown in the third graph of Fig. 8. It is an important feature of the control that the power delivered to the grid tends to be constant, given by
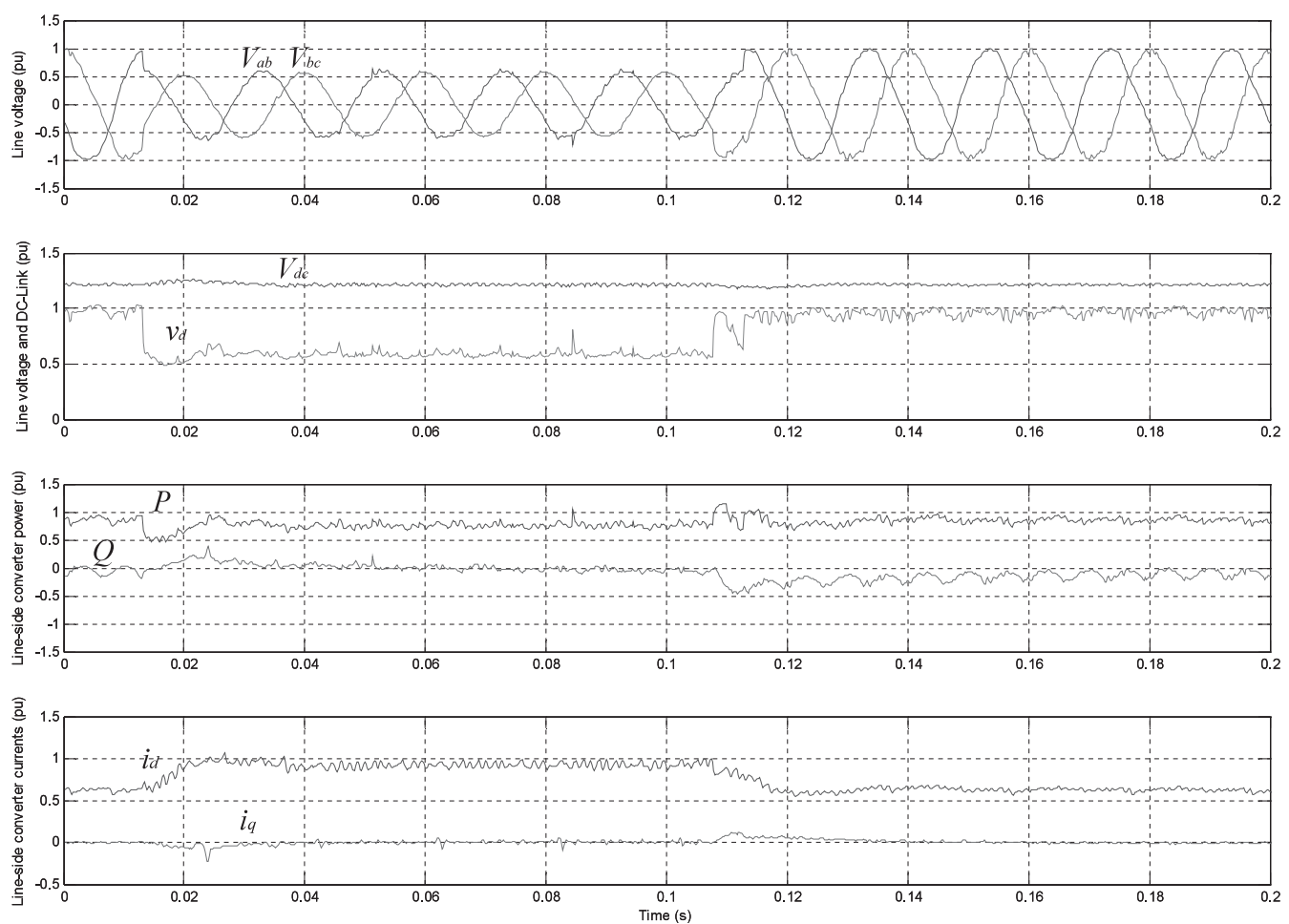

Fig. 8. Experimental results on the $55 \mathrm{~kW}$ set-up for the $50 \%$ voltage sag during $100 \mathrm{~ms}$ : Ilim $=1$ p.u. 

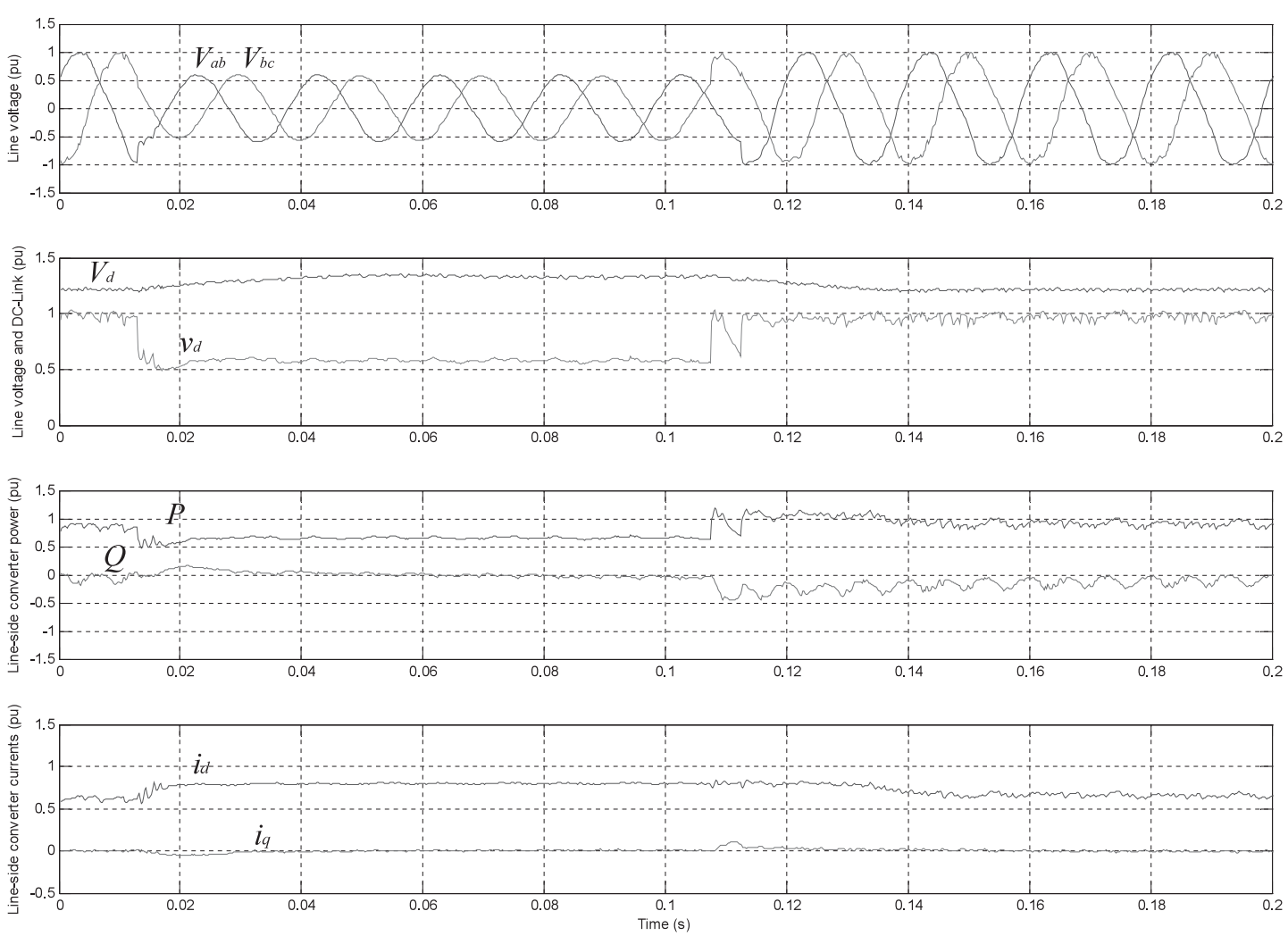

Fig. 9. Experimental results on the $55 \mathrm{~kW}$ set-up for the $50 \%$ voltage sag during $100 \mathrm{~ms}$ : Ilim $=0.8$ p.u.

the product of $V_{d}, I_{d}$ which gives approximately $50 \mathrm{~kW}$ using the VA appropriate base. The reactive power oscillates around zero which is expected because the control is programmed for unity power factor. In the last graph of Fig. 8, we can confirm this by observing the reactive current $i_{q} \cong 0$. We see also the direct component of the current out of the front end converter which increases up to its limit of 1 p.u. during the short circuit and thus tends to maintain constant the supply of power to the mains. Fig. 9 shows the measurement results in the case the current limit of the thre front end converter was set to 0.8 p.u. We see that the direct component of the current increases up to its limit of 0.8 p.u. and the power delivered to the grid is reduced accordingly. The DC link voltage increases as it can be observed in the figure because of the excess power from the generator that cannot be delivered to the grid due to the lower limitation ( 0.8 p.u.) of the current on the front end converter. The reactive power in both Fig. 8 and 9 does not immediately become zero because of the slow dynamic of the integral part of the current controller, but observing the figures carefully one relizes that $Q$ tends to zero as time passes getting almost zero at the end of the horizontal axis. If the experiments were performed within a longer time, then one could clearly see the reactive power becoming zero. Oscillations in the reactive power are most likely due to errors in the voltage measurements. In fact, the dominant oscillation has a frequency equal to three times the fundamental, which is typical when an offset is present in the measurement of one phase.

Among all the measurements, the DC link voltage is the most representative and relevant, because it shows the robustness of the converter control system during a $50 \%$ voltage reduction on the mains. This is a very desirable feature during severe short circuits because the capability to continue stable supply will strongly depend on the dynamics of the DC link.

In this paper only a symmetrical fault was tested in experiments. If an unbalanced voltage sag occurs, the converter has to apply an unbalanced output voltage for maintaining a balanced current. This is achieved by the ordinary "statcom" control system. The limitation is the bandwidth of the current controller which is decided by the necessary filtering of the measured signals. The tracking error will be seen as low frequency oscillation in the DC link voltage. This DC-voltage oscillation could be reduced by increasing the capacitance. Another type of fault is when a phase angle jump occurs there will be an error between the assumed active and reactive orientation and the real orientation. Thus the current controller will operate in a wrong orientation which will lead to instability in the dc-voltage. However, if the Phase Locked Loop is reacting fast, this can find the new phase angle before the voltage change in the dc-link is too large. The bandwidth of the PLL is mainly decided by the necessary filtering of the measured signals.

\section{Discussion}

In this paper we are showing the results of the control for a maximum symetrical voltage drop of $50 \%$ for two different cases of converter settings, and could observe that the DC link was still very stiff and there were good margins to inject the excess current into the network. However, for voltage sags deeper than $50 \%$ the control of the grid side converter might not be able to inject more current into the network because the current limit of the IGBT will be reached. In this case, the generator side converter will sense a DC link voltage threshold and that will activate the control of the 
electromagnetic torque aimed at reducing it in order to compensate for the power unbalance with the network. The speed of the turbine rotor can be allowed to increase up to a limit value, corresponding to the braking capabilities of the generator side converter. Some of the excess energy will therefore be stored as kinetic energy in the turbine itself. The relatively slow pitch control can help avoiding overspeed by reducing the incoming power from the wind.

When the sag approaches zero voltage, there can be some other possible solutions to counteract the excess of generating power from the wind turbine, especially if before the fault the wind turbine was operating near its nominal power. One of these solutions is to dimension the converters to withstand a certain level of over current and/or DC link capacitors to buffer the energy coming from the wind turbines. When designing the converters for over current care must be taken to not surpass the thermal limit of the grid lines. These solutions becomes unpractical if the sag is very deep, since the resulting converter would be extremely expensive and the amount of energy storage capability required for the capacitor has to be very high, and so would be the cost. Preferable solutions are: damping resistance on the DC link or damping loads on the wind farm site; maximizing the generator losses during fault in order to absorb as much power as possible from the wind turbine. This method can help when, in spite of all other countermeasures, the system is still close to its limits. Another particular solution depending on wind farm configuration is partial shut down of turbines in the wind farm to reduce the total output power during faults; this method applies to systems where multiple turbines are interconnected through a common DC-link, sharing a single grid-side inverter.

Superconducting magnetic energy storage systems SMES in the DC link to store the excess of generated power is another possibility. At present, however, this method is too expensive to be practical, but the technology can evolve and become practical in the future.

\section{Conclusion}

The voltage sag response of back to back converters of a wind generation system connected to the grid was experimentally analyzed. It is found in the experiment that down to $50 \%$ mains voltage reduction the DC link voltage is very stiff during the short circuit, being able to balance the power from the generator and the power on the grid side. Considering that wind turbines generators will trip when they detect a $30 \%$ voltage drop, the results shown in this paper are very promising with respect to the ride through capability.

The system in this paper was not tested under unbalanced faults or faults with a phase angle jump. The robust response of the system in these cases will be mainly limited by the filtering introduced in the PLL. The testing of the system under these conditions remains as a further stage in this research.

In the electrical system analyzed in this paper, in spite of the additional cost of power electronics converters and control, with the new grid codes the achievement of ride through capability is of relevance. Therefore, the additional investment will certainly be justified in this new scenario.

However, depending on the grid code to be adopted, it will be necessary to test the back to back converters for more severe voltage sags and this remains a subject for further investigation.

(Manuscript received May 9, 2005, revised March 17, 2006)

This paper was presented at IPEC-Niigata 2005, and approved for publication in the IEEJ Transactions on Industry Applications Society.

\section{References}

( 1 ) Eltra specifications: "Wind farms connected to the grid with voltages over $100 \mathrm{KV}$. Technical regulations for the properties and control of wind turbines", Eltra, Doc., Vol.6, No.17619, in Danish (2004)

( 2 ) Nordisk Regelsamling (Nordic Grid Code), Nordel (2004)

( 3 ) S. Bolik: "Grid requirements challenges for wind turbines", in Proc. Int. Work. Large Scale Integration Wind Power, Trans. Networks, Offshore Wind Farms, Billund Denmark (2003)

( 4 ) "Low voltage ride-thru technology", Tech. Notes, GE Wind Energy (2003)

( 5 ) S. Hartge and V. Diedrichs: "Ride-through capability of ENERCON wind turbines", in Proc. Int. Work. Large Scale Integration Wind Power, Trans. Networks, Offshore Wind Farms, Billund, Denmark (2003)

( 6 ) R. Cardenas and R. Pena: "Sensorless Vector Control of Induction Machines for Variable-Speed Wind Energy Applications", IEEE Trans. on Energy Conversion, Vol.19, pp.196-205 (2004)

( 7 ) R. Pena, R. Cardenas, R. Blasco, G. Asher, and J. Clare: "A cage induction generator using back-to-back PWM converters for variable speed grid connected wind energy system", IEEE IECON01 Proc., Vol.2, Denver, CO, pp.1376-1381 (2001)

( 8 ) M. Godoy, B.K. Bose, and R. Spiegel: "Fuzzy logic based intelligent control of a variable speed cage machine wind generation system", IEEE Trans. on Power Electron., Vol.12, No.1, pp.87-95 (1997)

( 9 ) J. Marvik, T. Bjørgum, B. Næss, T. Undeland, and T. Gjengedal: "Control of a wind turbine with a doubly fed induction generator after transient failures", 4th Nordic Workshop on Power and Ind. Electron. Proc., Norway (2004)

(10) R. Ottersten, A. Petersson, and K. Pietilainen: "Voltage sag response of PWM rectifiers for variable-speed wind turbines", 4th Nordic Workshop on Power and Ind. Electron. Proc., Norway (2004)

(11) M. Niemela: "Position sensorless electrically excited synchronous motor drive for industrial use based on direct flux linkage and torque control", Thesis for the Degree of Doctor of Science, Lappeenranta Univ. of Tech., Findland (1999)

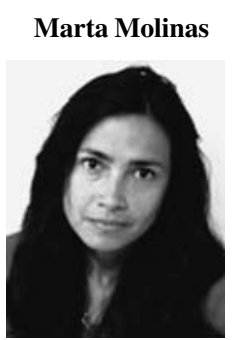

(Member) received the Diploma of Electro-mechanica engineer from the National University of Asuncion, Paraguay in 1992; MSc from Ryukyu University, Japan, in 1997, and Doctor of Engineering from Tokyo Insitute of Technology, Japan, in 2000. She is now with the Norwegian Unversity of Science and Technology engaged in the research of wind energy systems. Her interests include power electronics and electrical machines in power systems.

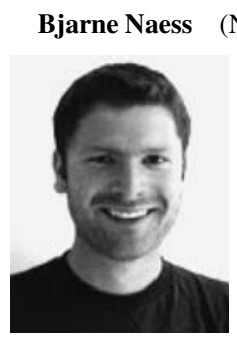

(Non-member) received the MSc in 2000 from the University of Minesota. He is currently working towards his $\mathrm{PhD}$ at the Energy Conversion group of the Norwegian University of Science and Technology. His interests include power system stablity and wind power generation systems. 
William Gullvik (Non-member) received the MSc from the Norwe-

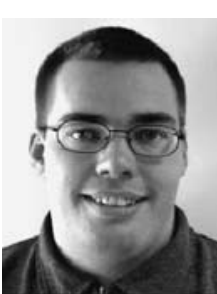

gian University of Science and Technology in 2001.

$\mathrm{He}$ is currently working towards his $\mathrm{PhD}$ at the Energy Conversion Group of the Norwegian University of Science and Technology. His interests inlcude power electronic converter topologies and advanced digital control.
Tore Undeland (Non-member) he is with the Norwegian University of Science and Technology as full Professor since 1987, and Adjunct Professor at Chalmers University of Technology, Sweden since 2000. He is currently president of the European Power Electronics society and member of the Norwegian Academy of Technological Sciences. His interests is in power electronics and wind energy systems. He is an IEEE Fellow. 